\title{
Mercado, política e cultura na "baixa” Amazônia: circuitos longos e curtos
}

\section{Market, politics and culture in the "low" Amazon: long and short circuits}

Fábio Fonseca de Castrol

Resumo $\mathrm{O}$ artigo discute os circuitos culturais presentes no espaço da "baixa" Amazônia - a área de ocupação ocidental mais consolidada da região - tendo por referência três grupos populacionais, compreendidos enquanto trajetórias sociais, que se diferenciam, entre si, por seu modo de ocupação econômica e cultural do espaço. Observa-se como duas dessas trajetórias sociais participam mais ativamente dos circuitos culturais, enquanto a terceira mostra-se mais reservada em relação a eles. Procura-se interpretar essas relações de aproximação e distanciamento a partir da experiência social intersubjetiva que os envolve.

Palavras-chave: Circuitos culturais; Amazônia; Produção cultural; Trajetória social; Mercado cultural

\begin{abstract}
This article discusses the cultural circuits present in the space of "low" Amazon - the more consolidated área, in the region, in terms of their Western occupation - with reference to three population groups, here understood as social trajectories, which differ among themselves by their way of economic and cultural occupation of space. We observe as two of these social trajectories participate more actively in cultural circuits, while the third shows up more reserved. We propose to interpret these relations of closeness and distance from the intersubjective social experience that involves them.
\end{abstract}

Keywords: Cultural circuits; Amazon; Cultural production; Social trajectory; Cultural market

\footnotetext{
${ }^{1}$ Universidade Federal do Pará - UFPA, Belém, PA, Brasil.

E-mail: fabio.fonsecadecastro@gmail.com
} 


\section{Introdução}

Qual o impacto dos circuitos culturais sobre a produção de novos localismos, na região amazônica de ocupação territorial mais tradicional - a da várzea dos grandes rios e do estuário paraense? De que maneira, as diferentes camadas da população amazônica se relacionam com esses circuitos culturais e, mais especificamente, como participam deles e como atuam para constituí-los? Partimos dessas questões para compreender o sistema de trocas e circulações de bens e informações culturais na parte mais habitada e de colonização antiga da Amazônia, a várzea estuarina - o arquipélago marajoara com os estuários dos rios Amazonas e Pará - e seus prolongamentos mais importantes: o nordeste do Pará, o baixo Tocantins e o baixo Amazonas. Como se trata do espaço de ocupação mais tradicional da região, as trocas culturais nele realizadas são mais intensas e possuem dinâmicas peculiares, favorecidas pelos tecidos midiáticos e comunicativos ali presentes, bem como por redes de troca e de consumo já consolidadas. Esse espaço, que aqui chamamos de "baixa" Amazônia, é um espaço de encontro e de hibridações culturais importantes: o mundo dos encontros entre inúmeras populações indígenas e também o mundo de etnocídios históricos, o mundo da Amazônia ribeirinha e quilombola, da Amazônia negra, das diversas experiências de colonização e da consolidação do Estado português, da guerra civil de 1835 e da borracha e, ainda, a Amazônia que encontra as musicalidades do Caribe e que experiencia o brega e outras sensibilidades marcadas pela ideia de artifício.

Desenvolvemos, inicialmente, uma série de mapeamentos e análises das estruturas de comunicação, massiva, comunitária e popular, na região (CASTRO 2012a; 2012b; 2013) e procuramos identificar não apenas as dinâmicas e estratégias midiáticas convencionais, centradas na ação tradicional das grandes empresas e agentes econômicos, mas, também, as estratégias alternativas, que caracterizam a cena comunicativa e cultural paraense. Em seguida, empreendemos uma cartografia dos circuitos e dos núcleos de produção artística e cultural, procurando 
entrever as práticas de troca neles existentes e como seus agentes integrariam com as estruturas de comunicação presentes na região.

Procuramos, assim, compreender o que identificamos como sendo o campo cultural-comunicativo regional, discutindo as relações entre as diferentes experiências sociais do espaço amazônico e a produção, reprodução e consumo da cultura.

Este artigo constitui um primeiro tratamento dessa etapa da pesquisa. Agregar os elementos conceituais para uma abordagem cartográfica e geopolítica da cultura amazônica. Pretendemos, assim, uma abordagem dos processos culturais e comunicativos levando em conta as dinâmicas socioeconômicas dos espaços e das populações locais.

Nesse horizonte, levamos em conta uma perspectiva histórico-geográfica, por meio da qual possamos identificar as formas, os padrões das relações sociais desenvolvidas em cada bloco da experiência social e histórica, em relação ao fazer cultural.

Nesse sentido, o artigo também deve ser compreendido como um esboço metodológico para uma tarefa de mapeamento e compreensão das cadeias econômicas da cultura na Amazônia, mas, em particular, nesse espaço que convencionamos chamar de "baixa Amazônia".

O trabalho constitui, portanto, um primeiro tratamento de resultados da observação apenas iniciada. São resultados ainda provisórios, mas que já permitem entrever o sistema de circuitos culturais da baixa Amazônia e, talvez mais que isso, indicar a dinâmica metodológica que pretendo seguir no decorrer da pesquisa.

Procuramos observar, neste trabalho, as tipologias e as topologias das práticas culturais de cidades médias da baixa Amazônia, principalmente no que se refere às formas sociais tomadas pelos circuitos culturais "curtos” - aqueles que, como mais à frente será definido, são fundamentados a partir da experiência social coletiva e da própria auto-organização dos lugares - por oposição aos circuitos culturais "longos", aqueles por meio dos quais se produz a hegemonia dos agentes culturais dominantes, como a indústria cultural sudestina e a comunicação massiva. 
Para isso, acompanhamos, através de observação participante e entrevistas abertas, fluxos e práticas culturais de representantes de três campos da sociedade amazônica, ou, para ser mais específico, seguindo a metodologia utilizada por Costa (2010), de três trajetórias sociais amazônicas.

$\mathrm{O}$ artigo se desenvolve em cinco tópicos. Após esta introdução, discutimos a noção de circuitos culturais, identificando, também, como essa noção pode ser aplicada na observação da baixa Amazônia. No tópico seguinte, procuramos explicitar, brevemente, o espaço da baixa Amazônia, identificando as variáveis que, a princípio, permitem compreendê-la como um locus com dinâmicas próprias, dentro da ampla cena regional. No quarto tópico, descrevemos três blocos sociais que selecionamos para poder colocar a questão aqui tematizada. Isso é feito por meio da noção de "trajetórias sociais" de Costa (2000), com o apoio de uma investigação de morfologia sociocultural por nós desenvolvida desde 2011 (CASTRO, 2011; 2014). No quinto tópico, enfim, procuramos, de maneira suscinta, projetar observações e hipóteses sobre a relação entre circuitos culturais e públicos da baixa Amazônia, por meio de um encadeamento geral das questões, que julgamos permitentes a serem colocadas, no âmbito de uma economia política da cultura, ao processo observado.

\section{Protocolo de observação dos circuitos culturais}

Barbosa (2009) compreende a cultura como uma rede de circuitos, caracterizados por capilaridade, mobilidade, descentramento, múltiplas articulações e interdependências. A cultura pode ser compreendida, dessa maneira, como um conjunto móvel e dinâmico de processos políticos, sociais, simbólicos, econômicos que, associados, conformam circuitos culturais (BARBOSA, 2009, p. 276).

O mesmo autor assinala duas vantagens no uso desse conceito de: reconhecer que os dinamismos da cultura são múltiplos e devem ser tratados em suas especificidades e enfatizar que os "circuitos culturais" são fenômenos sociais totais que envolvem, ao mesmo tempo, as dimensões simbólica, estética, social e econômica (BARBOSA, 2009, p. 276). 
O circuito cultural é um processo que envolve três momentos mais nítidos: produção, circulação e recepção, sendo que este terceiro momento pode envolver dinâmicas de consumo e de reconhecimento cultural. Nesse processo, interagem agentes culturais (os artistas, seus agenciadores, produtores, críticos, dentre outros) e também estão presentes formas de organização social, como a administração pública, o mercado, a sociedade civil e a comunidade.

Todos esses agentes atuam sobre a forma do circuito por meio de diferentes processos, mas se podem identificar dois processos sociais com impacto regulador sobre o circuito: as políticas culturais e a comunicação.

As políticas culturais têm um papel central sobre o circuito, pois exercem um poder regulador das formas de ação e das práticas estabelecidas, além, é claro, de constituírem uma de suas principais fontes de financiamento. Por sua vez, a comunicação - aqui compreendida tanto como a comunicação massiva quanto como aquela que, na contemporaneidade, é possibilitada pela tecnologia informática e que se conforma como cultura digital - exerce uma função de elo condutor na dinâmica organizativa do mesmo. Barbosa destaca o papel da comunicação, entre os elementos do circuito, como uma função central para o funcionamento do mesmo:

A coordenação ou comunicação dos agentes culturais entre si e entre estes e as instituições reguladoras torna-se a questão central das políticas públicas, já que envolve padrões de ação do setor público com relação ao dinamismo dos circuitos culturais e ao encadeamento dos eventos que formam os circuitos (BARBOSA, 2009, p. 276).

Assim, quando nos dispomos a compreender o funcionamento de um circuito cultural, precisamos levar em consideração a diversidade social dos agentes nele presentes, inclusive com seus conflitos e contradições e, também, esses dois fatores que possuem impacto regulador sobre o mesmo.

Também se faz importante observar as dimensões socioespaciais dos circuitos. Não se trata de compreender a dinâmica geográfica, ou 
espacial, presente na formação dos circuitos, mas, junto com elas, o recorte social dado a esse espaço. Especificamente, é preciso compreender como a desigualdade socioterritorial se faz presente no circuito, influenciando as trocas culturais. Nesse sentido, a proposta de Santos (1997) de que os lugares são definidos por meio de formas-conteúdo se mostra bastante útil para a compreensão desejada.

Santos, ajuda a problematizar a territorialização das ações sociais e, assim, a entender as dinâmicas espaciais como fluxos múltiplos, que obedecem a diferentes desejos de diferentes sujeitos sociais, dentre indivíduos, grupos deles e instituições as mais variadas.

Tratar-se-ia de elaborar uma topologia-tipologia do circuito, metodologia que foi empregada por Alves (2010) na sua interpretação do processo de territorialização de circuitos culturais de Recife. Por meio dessa abordagem, Alves observou os fixos e os fluxos informacionais organizados para a produção e difusão da cultura musical do Recife, procurando

aclarar quais são as conexões entre os circuitos informacionais descendentes, fundamentados em lógicas e normas estranhas aos lugares, e circuitos informacionais ascendentes, fundamentados na própria organização dos lugares (ALVES, 2010, p. 1)

Os circuitos curtos tendem a funcionar nas brechas das políticas culturais convencionais e utilizam formas de comunicão não hegemônicas, como a internet e suas redes sociais, blogues, sites locais, rádios comunitárias e livres, zines, divulgação "no boca a boca" - mas, também, eventualmente, a própria rede de comunicação hegemônica, quando ela se torna acessível a esses agentes sociais. Os agentes sociais dos circuitos curtos geralmente constroem estratégias de superação da fragmentação territorial do espaço social. Estratégias que, no campo das políticas culturais, dizem respeito à reivindicação pela democratização e regionalização dos processos de discussão e financiamento público da cultura e que, no campo da comunicação, dizem respeito a estratégias de adensamento das redes informativas. Os circuitos curtos tendem a 
ser mobilizados a partir de interesses comuns e, assim, a possuir uma dinâmica coletivista, ou cooperativista, de ação social.

Os circuitos longos, por sua vez, são constituídos por agentes sociais exógenos. Eles correspondem à lógica do grande mercado, das redes nacionais de comunicação, telecomunicações e produção de conteúdos e, também, à lógica das políticas culturais exclusivistas, autoritárias e centralizadas.

Os circuitos culturais longos são fundamentados em lógicas e normas estranhas aos lugares, à experiência histórica e social das populações envolvidas, enquanto que os circuitos curtos são fundamentados na própria organização dos lugares.

Com essa perspectiva, podemos indagar sobre o espaço, as mídias, as práticas, as dinâmicas e as formas tomadas por esses circuitos, tanto longos como curtos, a fim de melhor situá-los e compreendê-los.

Os espaços do circuito são as ruas, praças, mercados, livrarias, centros culturais, teatros, auditórios, cinemas, galerias, lojas de discos etc.

As mídias presentes nos circuitos são aquelas suportadas tanto pelos meios de comunicação massivos e convencionais, como rádio, TV, revistas e jornais como aquelas presentes na cultura tecnológica, digital, contemporânea, como nos telefones celulares, sites, redes sociais, blogues e microblogues etc. E ainda precisam ser consideradas as mídias móveis, como arquivos digitais e seus suportes flexíveis, como CDs, DVDs, pen-drives etc.

As práticas do circuito são tão diversas como a própria experiência social. Elas dizem respeito à maneira como os circuitos são utilizados. As redes sociais, por exemplo, ou a prática de gravação em estúdios fonográficos, ou, ainda, a cênica presente nos espetáculos. Um conceito que leva à noção de mediação, também uma forma de prática social, mas que permite indagar, mais especificamente, sobre a experiência social decorrente do uso das mídias. Dentre essas mediações, também elas extremamente variadas, pode-se exemplificar as mediações cotidianas que envolvem as ações de trabalhadores culturais, por exemplo: de 
que maneira eles lidam com os fluxos informativos e com os conteúdos transmitidos por meio desses fluxos?

Por fim, resta referir que a importância de discutir os circuitos culturais sob a perspectiva da economia política e com uma compreensão crítica da disputa espacial recai, pensamos, no fato de que esse tipo de abordagem permite compreender o processo cultural como uma ação coletiva e, assim, ajudar a subsidiar estratégias para a democratização das políticas públicas e dos fluxos comunicativos. Num outro plano, essa abordagem também permite compreender a cultura como o esforço resultante de uma complexa divisão social, territorial e técnica do trabalho.

\section{O espaço da baixa Amazônia}

A baixa Amazônia corresponde ao espaço de ocupação mais consolidado da região. É o espaço histórico da Amazônia colonial, que perdurou, como um sistema socioeconômico com características relativamente bem definidas, ainda que complexas, até o presente. É, em outras palavras, a sociedade da várzea. $\mathrm{O}$ espaço do modo de produção riberinho, das primeiras experiências urbanas, dos "aldeamentos" e do Diretório $^{3}$, do "descimento" dos índios ${ }^{4}$, dos latifúndios envolvidos na policultura ${ }^{5}$, dos criatórios bovinos e bubalinos, das drogas do sertão ${ }^{6} \mathrm{e}$ do látex. É o espaço da coleta como atividade econômica central, e de

\footnotetext{
2 Os "aldeamentos", na história amazônica, são modos de produção econômica com mão de obra indígena e gestão realizada por missionários religiosos. Agregavam populações étnicas diferentes entre si, capturadas pelo invasor europeu e acomodadas em simulacros de aldeias para o trabalho escravo.

${ }^{3}$ Entenda-se por Diretório o modelo de aldeamentos indígenas transformados em vilas e povoados após a expulsão da ordem religiosa dos jesuítas, dos territórios portugueses, em 1759.

4 "Descimento" é o termo com o qual a sociedade colonial amazônica do século XVIII representava as expedições de guerra e captura de populações indígenas, em geral refugiadas na Terra Firme por oposição à várzea, que aqui compreendemos como "baixa" Amazônia - para o trabalho escravo. ${ }^{5}$ A noção de latifúndio, na sociedade colonial do Grão-Pará, não é o modelo de plantation, reproduzido nos grandes sistemas de monocultura da história brasileira, mas o latifúndio de coleta, centrado na diversidade da produção econômica.

${ }^{6} \mathrm{O}$ termo designa o conjunto dos produtos naturais amazônicos, coletados pelas populações escravizadas e destinados à exportação, como cacau, guaraná, castanha-do-Pará, urucum, salsaparrilha, e várias outras ervas aromáticas e medicinais.
} 
múltiplas práticas sociais que decorrem, ou impactam sobre essa atividade econômica: a produção familiar, a partagem, a cultura do regatão e o aviamento ${ }^{7}$, em suas múltiplas formas. Mas não apenas: é, também, o espaço da industrialização "em franja”, dos aglomerados populacionais precários e de um imenso comércio informal.

A "baixa” Amazônia é, em síntese, a Amazônia histórica, fronteirizada, desde a década de 1960, pelo programa nacional-brasileiro de integração territorial da região - muito maior, efetivamente, que essa sociedade de várzea - à economia sudestina. A ocupação do espaço amazônico pela sociedade nacional brasileira possui variáveis específicas, que jamais se integram ou se harmonizam com a própria experiência amazônica tradicional. Essas variáveis correspondem aos modelos produtivos dos grandes criatórios extensivos, dos "Grandes Projetos" mineradores, da colonização forçada e de sistemas de crédito que, em sua essência, mesmo quando administrados por instituições regionais, como Sudam e Basa, não atendem às especificidades e às necessidades das populações da baixa Amazônia.

Na contemporaneidade da "baixa" Amazônia percebe-se a perduração das experiências sociais e dos modos de produção centrados na atividade extrativista, com recurso complementar de culturas de subsistência e/ ou temporárias. As estratégias econômicas patronais presentes nesse espaço são representadas, dominantemente, pelo extrativismo madeireiro e pelos empreendimentos agroflorestais (COSTA, 2012a; 2012b). Já as estratégias econômicas camponesas presentes nesse espaço praticam o extrativismo de produtos florestais associados às culturas temporárias de subsistência. No espaço com dominantes exógenas, por sua vez, perduram, nas estratégias econômicas patronais, as atividades intrusivas do agronegócio e da pecuária de corte e, nas estratégias econômicas camponesas, as lavouras associadas aos grandes projetos, a economia familiar e o pequeno criatório.

\footnotetext{
${ }^{7}$ Regatão é o barco de comércio tradicional da Amazônia, veículo de distribuição econômica de gêneros básicos e de produtos manufaturados. Aviamento é um sistema de crédito por meio do qual as mercadorias são fornecidas contra a prestação de mais valia e juros.
} 
As trocas entre esses espaços, embora intensas, contemporaneamente, também conservam conflitos e pontos de ruptura e tensão.

São dois macroespaços e, dessa forma, conservam peculiaridades próprias de suas experiênciais sociais. Porém, são dois espaços que se interprenetram permanentemente, por meio de trocas econômicas que se tornam, na sua cotidianidade, trocas simbólicas e culturais, conformando o aspecto da sociedade amazônica híbrida que, mais superficialmente, conhecemos.

O espaço da baixa Amazônia constituiria, grosso modo, uma mancha que se estende de Belém e do nordeste do Pará até quase Manaus, atravessando o rio Amazonas e penetrando no rio Tocantins até a altura de Tucuruí, no rio Xingu e no rio Tapajós e abarcando todo o estuário, com a ilha de Marajó e a maior parte do Amapá. Seu espaço central é o estado do Pará, espaço histórico mais antigo da Amazônia, o qual envolve, além de Belém, cerca de 90 dos 146 municípios do estado, envolvendo uma população que pode ser estimada em cerca de 5 milhões de indivíduos. No Amapá, essa faixa cultural alcançaria, pelo menos, 9 dos 16 municípios do estado, com uma população com cerca de 600 mil habitantes. No Amazonas, a baixa Amazônia alcança aqueles 11 municípios que possuem uma troca intensa com o baixo Amazonas paraense, com uma população de cerca de 330 mil habitantes.

Além da metrópole Belém (2,4 milhões de habitantes) e de cidades grandes, como Ananindeua (470 mil habitantes), Macapá (400 mil habitantes) e Santarém (300 mil habitantes) essa mancha territorial abriga outras oito cidades com população superior a 100 mil habitantes (Abaetetuba, Barcarena, Bragança, Cametá, Castanhal, Marituba, Santana e Parintins) e 15 cidades com população entre 50 e 100 mil habitantes (Acará, Alenquer, Benevides, Breves, Capanema, Capitão Poço, Igarapé-Miri, Moju, Monte Alegre, Óbidos, Oriximiná, Portel, Santa Isabel do Pará, São Miguel do Guamá e Tomé Açu).

Falar em baixa Amazônia constitui, naturalmente, uma abstração, que nos serve para descrever um espaço de trocas culturais dominado pelas indústrias cultural e criativa de Belém e de outras cidades paraenses, 
marcados, contemporaneamente, por intensa e criativa produção cultural e midiática. No primeiro grupo, pode-se referir as cenas tecnobrega, $z o u k$, melody e das guitarradas, para citar apenas os estilos musicais mais conhecidos. No segundo grupo, pode-se citar a importante cena midiática centrada em Belém e com distribuição nacional - a cidade é sede de duas redes religiosas nacionais de televisão, uma católica, a Rede Nazaré, e outra evangélica, a Rede Boas Novas - além de ser, também, sede de geradoras de televisão das Redes SBT e Record, notadamente a única capital amazônica na qual esses grupos possuem geradoras próprias (CASTRO 2012a; 2012b; 2013).

Pode-se estender esse espaço da baixa Amazônia até Manaus e subir pelos rios Negro e Purus, ou abarcar todo o Amapá, ou descer pelo rio Xingu. Se não o faço, é por tentar recortar um mapa que, em minha observação, tem mais coerência e leva em conta as características urbanas e culturais cosmopolitas atuais de Manaus ou a forma de ocupação do oeste do Amapá. Enfim, um recorte arbitrário, por meio do qual posicionamos nossa observação.

Da mesma forma, é necessário perceber que a baixa Amazônia não é um espaço social e cultural estanque, impermeável. Muito ao contrário disso, trata-se de um espaço de troca intensa e constante e, sobretudo, um espaço já penetrado por modos de produção exógenos à experiência amazônica. É em função disso que colocamos, nesta observação, uma trajetória social formada por esse modo exógeno de produção, a T-4 (COSTA, 2010), logo mais explicitada.

\section{Descrição dos grupos socioculturais observados}

As três parcelas da população amazônica que delimitamos são populações rurais e semirrurais e constituem grupos altamente significativos das formas de ocupação econômica do espaço amazônico. Uma dessas parcelas se caracteriza por práticas altamente predatórias em relação ao meio ambiente, já que representa o primeiro grupo de indivíduos procedente de outros espaços geográficos e sociais brasileiros que, economicamente, estabelecem-se no espaço amazônico, tendo por base 
atividades madeireiras que convergem, com os passar dos anos, na direção da pecuária de corte extensiva. O segundo grupo populacional representa, por sua vez, os indivíduos plenamente participantes de um modo de produção, digamos, amazônico, caracterizado pela exploração sustentável, coletiva e em base familiar, dos insumos da floresta. São populações amazônicas tradicionais, em geral, não compreendidas pelo sistema de financiamento produtivo do aparelho estatal brasileiro e ignoradas pela opinião pública mediana nacional.

O terceiro grupo - que não consta da investigação de Costa (2010) e que é uma projeção que fizemos em nossa própria pesquisa - é constituído por uma parcela de indivíduos de renda mediana, estabelecidos em espaços urbanos de média dimensão (cidades com população entre 100 mil e 230 mil habitantes), que, segundo os especialistas, constituem o grupo social regional que, associado num processo econômico explicado como "redes de cidades", conformam uma parcela altamente significativa da economia regional e, provavelmente, são o principal sustentáculo para um futuro sustentável da floresta amazônica. O Quadro 1 sintetiza esses três grupos de indivíduos:

\begin{tabular}{lll}
\hline Grupo Descrição topográfica & Descrição sociográfica \\
\hline T-4 & Sistema de famílias associadas & Esse grupo social na Amazônia corresponde \\
à atividade econômica patro- & ao modelo de produção imposto à Amazônia \\
nal que surge como exploração & pelo regime militar e, até hoje, mantido com \\
de produtos madeireiros, con- & subvenção pública, por meio de créditos aba- \\
vergindo para o plantio de & lizados por especialistas em desenvolvimento \\
culturas temporárias e conso- & que determinam as políticas de fomento. \\
lidando-se, economicamente, & Segundo Costa (2009), esse grupo é compos- \\
na atividade da pecuária de & to por 27.831 estabelecimentos, que ocupam \\
corte. & $59,7 \%$ da área privatizada da Amazônia, o \\
& equivalente a 33,3 milhões de hectares. Cada \\
& propriedade tem, em média, 1,2 mil ha e, em \\
& seu conjunto, empregam 10,5\% dos trabalha- \\
& dores rurais e produzem 25\% do valor bruto da \\
& produção rural (VBPR) amazônica. \\
\hline
\end{tabular}




\begin{tabular}{lll}
\hline Grupo & Descrição topográfica & Descrição sociográfica \\
\hline T-2 & Sistema de famílias associadas & Esse grupo social conforma o padrão mais tra- \\
à atividade econômica cam- & dicional da economia amazônica, constituindo \\
ponesa, que têm por base o a expressão de um paradigma tecnológico que & extrativismo não madeireiro & pressupõe a preservação ambiental. \\
em combinação com agri- & Costa (2009) estima a existência de 130.593 \\
cultura diversa, ou seja, um & estabelecimentos camponeses desse tipo na \\
sistema familiar agroflorestal. & Amazônia. Eles ocupam uma área com 3 mi- \\
& lhões de hectares. Cada propriedade possui \\
& uma dimensão média de 23 ha, dos quais, \\
& apenas $1 / 5$, em média, é usado para atividade \\
& agropecuária. \\
& Ainda de acordo com Costa (2009), esse siste- \\
& ma emprega 502 mil pessoas e representa 21\% \\
do VBPR.
\end{tabular}

A-12 $2^{8}$ Sistema de famílias associadas Na região amazônica, esse grupo social corresà atividade econômica ren- ponde a cerca de 37,2\% da população e detém tista urbana, com padrão de $31 \%$ da renda regional. Possui forte relação sorendimentos mensais na faixa cioeconômica com o meio rural e, ao mesmo (familiar) entre R\$1.115,00 tempo, conforma padrões de urbanização, em e R\$4.807,00; sem nenhum curso, de grane impacto regional.

componente formado em curso superior e habitante de cidade com população maior que 100 mil e menor que 230 mil habitantes.

Quadro 1. Grupos socioculturais observados

Fonte: Costa (2010, 2012a, 2012b).

A questão central de nossa observação diz respeito à maneira como os indivíduos de cada uma destas trajetórias sociais se coloca em relação aos circuitos culturais presentes em seu espaço social e, mais especificamente, em relação às rotas curtas destes circuitos. Também desejamos indagar sobre a forma como essas trajetórias produzem estratégias de uso, apropriação e discussão a respeito dos processos sociais com impacto regulador sobre o circuito: as políticas culturais e a comunicação.

8 Utilizamos nas duas primeiras linhas a classificação construída por Costa (2010, 2012a, 2012b), adotando a designação "T", de Trajetória, tal como trabalhada nesse autor. Na terceira linha utilizamos o designativo "A", por nós construído em survey de pesquisa e modelo exploratório. 


\section{Síntese da observação}

Toda a baixa Amazônia é carente de espaços culturais especializados, como museus, teatros, cinemas e bibliotecas. Neste sentido, apenas Belém possui uma estrutura cultural importante e mesmo representativa, de toda a Amazônia. Não obstante, os espaços culturais não especializados são inúmeros, e estão presentes em todos os lugares. Refiro-me à praça pública, à feira e a rua; às festividades religiosas; às orlas e avenidas beira-rio de toda a baixa Amazônia; aos galpões e terreiros de festa; aos "balneários", igarapés e clubes; aos centros comunitários e espaços de convívio e sociabilidade improvisados etc.

Também as práticas culturais e as estratégias de mediação presentes nesses espaços são variadas. A música e o baile são, de longe, a manifestação cultural que mais adensa o circuito. O múltiplos subgêneros do brega, das guitarradas, aparelhagens, carimbó e de outras músicas paraenses estão presentes na vida cotidiana de toda a baixa Amazônia, conformando um amplo circuito de produção, distribuição e uso que inicia, normalmente, em Belém, por meio da produção do conteúdo musical e dissemina-se numa rede de distribuição, a qual conta com um mercado ativo baseado numa rede de shows que alcança milhões de reais, anualmente.

Quando observamos, comparativamente, as três trajetórias sociais destacadas, em termos de sua inserção dos circuitos culturais amazônicos, fica evidente a proximidade entre a T-2 e a A-12. Ambas são camadas populacionais características do espaço aqui identificado como baixa Amazônia. Suas perspectivas de vida e visões de mundo se conformam a partir de tipificações socioculturais produzidas por meio de uma experiência histórica de longa duração. Os usos feitos dos mecanismos da política cultural e das formas e meios de comunicação são bastante variados, entre essas duas trajetórias sociais, mas se pode perceber que, ambas, permitem a fruição dos circuitos curtos.

Por sua vez, a trajetória compreendida como T-4 tende a realizar o movimento contrário: tende a reforçar e respaldar os circuitos longos. Em termos práticos, isso significa, por exemplo, que os indivíduos dessa 
trajetória não estarão presentes, em geral, numa festa de aparelhagem tipicamente paraense, ou que não consumirão, da mesma maneira, dentro do mercado de CDs e DVDs piratas com os astros regionais, ou que participarão de trocas econômicas menos importantes por ocasião de festas populares e/ou religiosas tradicionais. Eles tentarão afirmar, por exemplo, gêneros musicais mais afeitos à experiência cultural das zonas rurais extensivas do país, como o sertanejo.

As razões socioeconômicas para essa forma de reação são evidentes: os componentes da trajetória não pertencem, em geral, ao espaço da baixa Amazônia. Foram para lá levados pela pressão do capital sobre a floresta amazônica.

Essa diferença de práticas, costumes e gostos gera processos de fronteirização social que, apesar de possuírem potenciais formas conflitivas, também possuem trocas e experiências de diálogo enriquecedoras para toda a sociedade.

O impacto dos circuitos culturais paraenses sobre a A-12 parece ser gigantesco. É nessa trajetória social que encontramos maior variedade de práticas sociais de autogestão dos processos culturais e comunicacionais e imensa receptividade para o conteúdo cultural produzido na própria região. Trata-se de um localismo, sim, mas de um localismo híbrido, o que parece ser a própria condição da sua existência. Híbrido porque mescla, por exemplo, a cultura das festas de aparelhagem com a programação televisiva dos programas de auditório. Porque mescla o pop internacional com as guitarradas locais. Com isso, o circuito se dinamiza e se revitaliza, a ponto mesmo de reinventar os modos de troca econômica.

As práticas culturais, associadas à tecnologia e aos processos de sociabilidade da A-12 geram, também, uma perspectiva de reformulação da tradicional forma de mostrar a comunicação em seus efeitos sociais: já não se torna central discutir os efeitos da mídia sobre a sociedade, mas sim o contrário, numa perspectiva que evoca a discussão feita por Gushken (2008). Esse autor afirma, por exemplo, que, 
Se considerarmos a comunicação em sua força paradigmática na constituição da cultura contemporânea, pode-se perceber como, nos movimentos sociais e culturais, o pensamento comunicacional e expressivo emerge ao modo de práticas de produção de linguagem em gêneros variados, que vão das artes eruditas ao artesanato, da linguagem oral à linguagem visual e musical, quando não do cruzamento entre elas (GUSHIKEN, 2008, p. $10)$.

Outra questão interessante a abordar diz respeito à função desses circuitos culturais na produção de novas experiências territoriais e identitárias - ou, ainda, na produção dos novos localismos. Hall (2001) e Naisbit (1994) observam como a produção de novos localismos resulta, dialeticamente, da expansão da sociedade globalizada. Esse processo consistiria, a princípio, na própria rota ascendente dos circuitos culturais, ou seja, na própria territorialização, ou melhor, reterritorialização do espaço tomado pelas rotas longas, à medida que estas tendem a se associar ao capital nacional e/ou global, contra a experiência de localização das coletividades locais.

Porém, naturalmente, esse jogo de experiências locais constitui-se como esferas de experiência superpostas, e sempre se poderá falar de localismos mais locais que outros. Dentro do espaço aqui definido como baixa Amazônia, existem territorializações internas: diferentes e concorrentes territórios de identidade que produzem novas demandas locais e novas territorializações, com impacto, certamente sobre os circuitos culturais.

Também nos parece importante referir o papel das cidades, ou das redes de cidades, na produção dos novos localismos e, em consequência, na conformação dos circuitos culturais. Na Amazônia, as cidades ocupam uma função socioeconômica decisiva, à medida que, além de constituírem a forma mais tradicional de ocupação ocidental do território, funcionam, historicamente, como uma rede natural de proteção ambiental - já que a ruralização do espaço amazônico resulta no maior impacto conhecido sobre a floresta virgem. Como coloca Becker (2009), as cidades defendem o coração florestal à medida que contêm a 
dispersão da atividade econômica, sobretudo quando formam redes de geração de serviços e agregam valor à bioprodução.

Os circuitos culturais têm, nas cidades, seu principal espaço de multiplicação e de produção simbólica. Talvez porque as cidades funcionem como ponto de interseção entre diferentes escalas locais, nacionais e transnacionais.

Enfim, cabe observar que as políticas culturais precisam levar em consideração as dinâmicas locais para não se tornar, simplesmente, instrumento de validação dos circuitos longos. No caso da Amazônia essa preocupação tem sido recorrente, por parte dos produtores culturais, quando, por exemplo, reivindicam compensações para o "custo amazônico" - que outro senão a equação econômica e política presente na lógica e nos desafios dos circuitos curtos.

\section{Referências}

ALVES, C. N. Os circuitos de informações no território: a produção musical em Recife. In: Anais do XVI Encontro nacional dos Geógrafos. Crise, praxis e autonomia: espaços de resistências e de esperanças. Porto Alegre, 25-31 jul. 2010.

BARBOSA, F. Boas intenções, poucos recursos: balanço das políticas culturais brasileiras recentes. Proa - Revista de Antropologia e Arte, v. 01, n. 01, ago. 2009. Disponível em: http://www.ifch.unicamp.br/proa/debates/debatefrederico.html. Acesso em: 15 maio 2012.

BECKER, B. Uma visão de futuro para o coração florestal da Amazônia. In: BECKER, B.; COSTA, F. A.; COSTA, W. M. Desafios ao Projeto Amazônia. Brasília: Centro de Gestão e Estudos Estratégicos (CGEE), 2009. p. 215-363.

CASTRO, F. F. Capital social, comunicação e desenvolvimento na Amazônia. Relatório Parcial de Desenvolvimento de Pesquisa. Belém: UFPA, 2011.

CASTRO, F. F. Geopolítica da comunicação na Amazônia. Comunicação ๒ Sociedade, v. 57, n. 1, p. 151-171, 2012.

CASTRO, F. F. Sistemas de comunicação na Amazônia. Fronteiras - Estudos Midiáticos, v. 14, n. 3, p. 179-191, 2012.

CASTRO, F. F. Macrodinâmicas da comunicação midiática na Amazônia. Boletim do Museu Paraense Emílio Goeldi. Ciências Humanas, v. 8, n. 2, p. 435-445, 2013. 
CASTRO, F. F. Experiência social, cultura e sensibilidades amazônicas. Relatório Parcial de Desenvolvimento de Pesquisa. Belém: UFPA, 2014.

COSTA, F. A. Desenvolvimento Agrário Sustentável na Amazônia: Trajetórias tecnológicas, estrutura fundiária e institucionalidade. In: BECKER, B.; COSTA, F. A., COSTA, W. M. Desafios ao Projeto Amazônia. Brasília: Centro de Gestão e Estudos Estratégicos (CGEE), 2009. p. 215-363.

COSTA, F. A. Mercado e produção de terras na Amazônia: avaliação referida a trajetórias tecnológicas. Boletim do Museu Paraense Emílio Goeldi. Ciências Humanas, v. 5, n. 1, p. 25-39, 2010.

COSTA, F. A. Economia camponesa nas fronteiras do capitalismo: teoria e prática nos EUA e na Amazônia Brasileira/Francisco de Assis Costa. Belém: NAEA, 2012a.

COSTA, F. A. Elementos para uma economia política da Amazônia: historicidade, territorialidade, diversidade, sustentabilidade/Francisco de Assis Costa. Belém: NAEA, 2012b.

HALL, S. A identidade cultural na pós-modernidade. 5. ed. Rio de Janeiro: DP e A, 2001. GUSHIKEN, Y. Usos midiáticos na constituição de circuitos culturais e comunicacionais populares urbanos. Revista da Associação Nacional dos Programas de Pós-Graduação em Comunicação. E-compós, Brasília, v. 11, n. 1, p. 1-15, jan./abr. 2008.

NAISBITT, J. Paradoxo global. Rio de Janeiro: Campus, 1994.

SANTOS, M. A natureza do espaço: técnica e tempo, razão e emoção. São Paulo: Hucitec, 1997.

\section{Sobre 0 autor}

Fábio Fonseca de Castro - Pós-doutor pela Université de Montréal. Doutor em sociologia pela Université de Paris 5 (Sorbonne-Descartes). Programa de Pós-graduação em Desenvolvimento Sustentável do Trópico Úmido (PPGDSTU), do Núcleo de Altos Estudos Amazônicos (Naea, UFPA) e na Faculdade de Comunicação da UFPA.

ORCID: http://orcid.org/0000-0002-8083-1415

Data de submissão: 03/09/2015

Data de aceite: 19/08/2016 